\title{
Innovative analysis methods of the Perinatal pedagogy
}

\author{
Elena Egorova*, Anna Neydorf, and Ekaterina Davydova \\ Don State Technical University, 344002, Rostov-on-Don, Russia
}

\begin{abstract}
The scientific discourse does not consider the possibilities of preparing pregnant women for interaction with medical personnel during childbirth by means of perinatal pedagogy. Purpose of the study: To determine the key problems of interaction between women in labor and the staff of medical institutions (maternity hospitals) and their causes, the elimination of which could be facilitated by perinatal pedagogy. The study was conducted by the method of content-analysis of interviews of 24 women. The main topics were identified that describe the negative experience of women in childbirth: neglect of medical personnel, ignoring requests for information on the state of the mother and child, psychological pressure and manipulation, compulsion to medical intervention, corruption, extortion. Also, 4 types of women's emotional reaction to the situation were identified: positive, unemotional, negative (low and high intensity). Analysis gives reason to believe that the main cause of psychological trauma is not the experienced events, but the attitude towards them. Perinatal pedagogy can reduce the trauma of birth experience by increasing medical literacy and legal awareness of pregnant women, through training and practical training, irradiating the methods of communication with medical personnel. Psychological birth trauma in women is largely determined by negative experience of interaction with the staff of medical institutions. More detailed statistical studies of the factors that enhance the negative emotional reaction to this experience and the development of methods for preparing pregnant women for it are needed.
\end{abstract}

\section{Introduction}

In the scientific discourse, the problem of psychological trauma to women at the stage of childbirth and postpartum care is widely discussed. This interest is motivated primarily by the fact that it has been repeatedly proven that there is a direct connection between the attachment of the mother and the child and the psychological experiences of the mother caused by the process of childbirth [1]. In addition, the influence of traumatic birth experience on the formation of the mother's role, the change in the social role of the woman, the deterioration of relations with the spouse, the ability to make decisions, and even the psychological ability to have another child have been proven [2].

\footnotetext{
*Corresponding author: filonovaei@ya.ru
} 
Based on the analysis of research carried out by scientists from different regions of the planet, three groups of factors can be distinguished that affect the psychological trauma of women in labor during childbirth:

1) Activities of medical personnel.

So, according to the observations of the midwives themselves, the medical staff is not attentive enough. Midwives should better monitor and support their patients' psychological well-being [3; 4]. A factor is the communication problems of medical personnel: failing to recognise and meet the human needs of of patients [5]. Another factor is too active and sometimes unnecessary medical intervention, such as a vaginal examination [6] or a cesarean section [7]. Research shows that many couples make decisions to give birth at home as a result of negative experiences with health care providers [8].

2) Subjective and objective factors on the part of women in labor.

In particular, communication problems are two-sided: failing to recognize and meet human needs is manifested not only by midwives in relation to women in labor, but also by women in labor in relation to midwives [5].

Psychological comfort during and after childbirth is influenced by age, education, order of childbirth and experience of previous childbirth, and the woman's material security [9].

However, it should be noted that this group of factors is the poorest in the scientific literature. As a rule, factors of this group are mentioned in connection with studies of factors from the first and third groups.

3) Sociocultural factors.

These are factors of a higher level. These factors determine the society's attitude towards pregnancy, childbirth and motherhood, the behavior of physicians, their vision of their role in obstetrics, their attitude to their condition, their understanding of what is happening and their attitude to it, the role of the woman in labor and the staff of medical institutions in the process of childbirth, etc.

For example, Patterson et al. Speak of "toxic cultures" that determine the behavior of medical personnel [5]. Another sociocultural factor is the epistemological prerequisites of a patriarchal society, which prevent women from recognizing medical interventions (in particular, vaginal examination) as violence, although it is physically experienced as such [6].

Sociocultural characteristics - the combination of knowledge circulating in the public consciousness, worldview, ideas about the norm - also directly affect medical practices, such as the preference for natural childbirth by caesarean section and the choice in favor of epidural anesthesia. The medicalization of childbirth is one of the factors of traumatization, the influence of which can be reduced, according to researchers, by means of "cultural awareness through the mass media, informing women of the long-term complications of cesarean, and physical and mental preparation of the mother" [7].

In general, the concept of "healthy pregnancy" is a composite sociocultural complex, not just a medical phenomenon, and includes the care of society, family, employer for a pregnant woman, and public well-being in general [10].

Thus, the following three components can be named as factors for successful nontraumatic childbirth in a medical institution:

- minimal medical intervention (only if necessary) [4];

- competent accompaniment and support before and during childbirth [9];

- ensuring a comfortable sociocultural situation (support from society and public institutions, education, sufficient income, etc.) [10; 5; 9].

In the scientific discourse, not only the theoretical aspects of the problem of traumatic birth experience are considered, but also practical tools are developed and tested for diagnosing the problem and its prevention. For example, methods for assessing stress during childbirth are being developed (see, for example, [11]). Many publications are 
devoted to the formation of a more humane attitude towards women in labor among medical personnel (for example, [12]), as well as the problem of the practical formation and implementation of new ethical principles in the work of medical personnel (for example, [13]).

Another aspect of this issue is the preparation of pregnant women and their partners for childbirth. Various trainings, psychological and psycho-samatic practices for pregnant women and their partners are being studied, aimed at reducing anxiety, fear, pain during childbirth. Trainings "Gave them [parents] a sense of security and manageability" [14 p. 12], can reduce fear of childbirth [15], and generally reduce the psychological trauma of childbirth [16].

Thus, scientific publications propose two practical approaches from the standpoint of perinatal pedagogy:

1) training of medical personnel, increasing their responsiveness and attentiveness towards women in labor, their ethical training;

2) training for mothers or both parents, including informing about the physiology of the birth process, teaching physiological techniques that relieve pain, etc.

Also, as has been shown, some researchers mention a third approach, but exclusively from a theoretical standpoint: sociocultural. The need for changing sociocultural conditions is stated, but practical recommendations are not given on how to implement this. Moreover, we are not talking about approbation of any methods within the framework of this approach.

And although some studies indicate the importance of subjective factors of women's well-being and readiness for childbirth, as well as sociocultural factors, including a woman's education, her attitude to her body, motherhood, knowledge about the physiology of pregnancy and childbirth researchers do not offer specific methods of influencing these components women's well-being.

Moreover the issue of preparing pregnant women for the process of communication with the staff of medical institutions is not discussed anywhere. But it is precisely this aspect - the trauma of women in labor by the very fact of interaction with a medical institution and its personnel - that interests us primarily.

Research hypothesis: we assume that for Russian women in childbirth, a huge stress and often traumatic experience is interaction with the staff of medical institutions during and after childbirth, the reason for which is the unpreparedness of future mothers for this contact.

Purpose of the study: to determine the key problems of interaction between women in labor and the staff of medical institutions (maternity hospitals) and their causes, the elimination of which could be facilitated by perinatal pedagogy.

\section{Materials and methods}

The study was conducted by the method of oral interviewing, based on the results of which written summaries were drawn up. 24 women aged 20 to 60, who gave birth in maternity hospitals, were asked to freely describe their birth experience, with an emphasis on the experience of interacting with the staff of the medical institution. Cases that took place at different times were considered. The earliest of these dates back to 1981, the latest in August 2020. Such time coverage is necessary in order to get a general idea of the dynamics in the studied area. All women interviewed gave birth in medical institutions in Rostov-on-Don and the Rostov region. Participation in the study was voluntary. All participants provided written consent for the use of materials obtained during the study in scientific publications. 
The materials of the interviews were subjected to content analysis: the key most characteristic topics that were encountered in interviews of 12 or more respondents were identified. The initial goals and objectives of the study did not involve assessing the intensity and depth of the respondents' emotional reactions. However, when analyzing the materials, obvious differences were revealed, which became the basis for dividing the interviewees into 4 groups according to the severity of emotional reactions. Analysis of demographic factors, sociocultural factors and circumstances of childbirth made it possible to make a number of assumptions about the factors affecting the intensity and severity of emotional reactions.

\section{Results}

Content analysis of interviews with 24 women in labor revealed the following key topics related to the facts of interaction with the staff of maternity hospitals:

- Rudeness and neglect of medical personnel

- Ignoring requests for information on the state of the mother and child (also ignoring the wishes of the woman in labor, ignoring the patient by the doctor with whom a preliminary agreement was reached)

- Psychological pressure and manipulation, including threats, for example, leaving without medical supervision and assistance

- Coercion to medical intervention without obvious medical indications

- Corruption, extortion.

Two interviewees described their experience as positive, without traumatic components and not causing negative emotions.

Here are some excerpts from interviews that reflect the main themes identified and women's perception of the situation.

Rudeness and neglect:

- At 34 weeks my water broke. I arrived at the reception. I was told: "Why did you come so early? You still have to walk and walk! Only in vain did I wake people up! " (A., 21 years old, childbirth in 2020 at the age of 21)

- The doctor growled: why are you shouting! You should have thought when you fucked (in fact, he used a harsher word)! And now there is nothing to shout here (I., 43 years old, born in 2000 at the age of 23)

Each time I was afraid that my children would be confused, because this happened to others more than once. (L., 60 years old, last birth in 1989 at the age of 29)

- Our children were confused ... And you know, the nurse still tried to prove to us that no one confused anything, that we were given the children we need (A., 39 years old, childbirth in 2003 at the age of 22)

- After giving birth, I did not have the strength not only to get up, but even to say something. I was very dehydrated. But the medical staff did not care at all. No one even came up to me until the next round (N., 35 years old, childbirth in 2009 at the age of 24)

- I was amazed at how they treated all women in childbirth in the hospital: as if they were a hindrance, came and interfered with the doctors' work. Not just pieces of meat - at least they lie silently and do not interfere, but much worse (T., 37 years old, childbirth in 2015 at the age of 32)

Ignoring requests for information on the condition of the mother and child:

- Various nurses came to me several times and injected something. When asked what they were doing, they did not answer. They ignored me altogether, as if I were background noise (A., 39 years old, born in 2003 at the age of 22) 
- After giving birth, the child was immediately taken away from me without explanation and brought only on the third day. They simply kept silent to my attempts to talk to the medical staff (A., 21, birth in 2020 at the age of 21)

Psychological pressure and manipulation:

- They examined me and began, without explaining anything to me, yelling in front of me that she was old-born (at that time I was 30 years old), that I would have to pull the child with forceps and definitely need to do a Caesarean section (E., 35 years old, childbirth in 2015 at the age of 30)

- The doctor said that since I do not agree with his appointments, he is removed, and I can give birth myself and do what I want: no one from the hospital staff will come to me again (T., 37 years old, childbirth in 2015 at the age of 32 years old)

Coercion to medical intervention without obvious medical indications:

- Having survived the abdominal operation, I could not understand for a long time what happened to me, I could not (and cannot) accept the suture and the fact that I, a healthy person, had been operated on (E., 35 years old, childbirth in 2015 at the age of 30)

Corruption and extortion:

- I have not been removed from the delivery table yet, and the midwife has already said impudently: hey, you don't want to thank me? And she did not mean "thank you" at all (A., 39 years old, childbirth in 2003 at the age of 22)

- The nurse ... says: give me 200 rubles. I brought you a parcel. And so it was all the time. Even the cleaning ladies demanded bribes (L., 38 years old, gave birth in 2002 at the age of 20).

In terms of readiness for childbirth and meeting medical care, the following types of experiences were identified:

- joyful expectation, devoid of anxiety and fear, coupled with the confidence that everything will be fine;

- fear of childbirth as of something new and unknown (typical for those giving birth for the first time);

- anxiety for your health and the health of your child;

- anxiety associated with sociocultural factors (rejection by the family, danger to a career, having a child without the support of a partner);

- calm expectation based on experience and awareness.

The analysis of the interviews showed that among the surveyed women, 4 types of emotional reactions to interaction with the staff of a medical institution were common:

- Positive (gratitude, joy from the birth of a healthy child);

- Emotional - a rational approach to assessing the situation (women described the negative components of the experience and designated this experience as negative, but did not show signs of negative emotions);

- Negative (low intensity) ("it was bad", "leaves much to be desired");

- Negative (high intensity) ("terrible", "I will never forget this nightmare in my life"). The following are the statements of the respondents characterizing their experience:

- It wasn't perfect. But the babies are worth it (V., 42 years old, a mother of four, who had a cesarean section every time for medical reasons, the last birth in 2018 at the age of 40).

- Every time I think about the possibility of having a second child, the last argument is the memory of a week in the hospital. I will not agree to repeat this experience for anything in the world (A., 39 years old, childbirth in 2003 at the age of 22 years)

- After giving birth, a few months later, I realized that I could not cope with these experiences on my own. I underwent psychotherapy for about a year. But I cannot say that I have completely outlived this situation (T., 37 years old, childbirth in 2015 at the age of 32). 
It was found that the emotional reaction does not depend on the facts, that is, on the events experienced by the women in labor. One of the respondents of the first group and all the respondents from the second group described all or some of the facts that caused a negative reaction in other interviewees, but they treated these facts in a completely different way. Thus, it is not the very interaction with the staff of the medical institution that is traumatic, but how the woman in labor relates to the situation.

Table 1 shows demographic and some socio-cultural indicators of respondents belonging to a particular group (according to the criterion of emotional reaction to interaction with the staff of maternity hospitals).

Table 1. Demographic and sociocultural characteristics of the respondents. Distribution into groups depending on the emotional reaction to interaction with the staff of maternity hospitals.

\begin{tabular}{|c|c|c|c|c|}
\hline $\begin{array}{c}\text { Emotional } \\
\text { reaction }\end{array}$ & Positive & \begin{tabular}{|c|}
$\begin{array}{c}\text { Emotionles } \\
\mathrm{s}\end{array}$ \\
\end{tabular} & $\begin{array}{c}\text { Negative (low } \\
\text { intensity) }\end{array}$ & $\begin{array}{c}\text { Negative (high } \\
\text { intensity) }\end{array}$ \\
\hline $\begin{array}{c}\text { Number of } \\
\text { respondents }\end{array}$ & 2 & 5 & 12 & 5 \\
\hline $\begin{array}{l}\text { Age at the time } \\
\text { of the interview }\end{array}$ & $20-25$ & $33-60$ & $23-43$ & $28-41$ \\
\hline Education & $\begin{array}{l}\text { Secondary, } \\
\text { incomplete } \\
\text { higher }\end{array}$ & $\begin{array}{l}\text { Secondary } \\
\text { vocational } \\
\text { or higher }\end{array}$ & $\begin{array}{c}\text { Secondary } \\
\text { vocational or } \\
\text { higher }\end{array}$ & $\begin{array}{l}\text { Higher (several } \\
\text { higher) or the } \\
\text { presence of an } \\
\text { academic degree }\end{array}$ \\
\hline $\begin{array}{l}\text { Amount of } \\
\text { children }\end{array}$ & 1 & $2-4$ & 1 & $1-2$ \\
\hline $\begin{array}{l}\text { Supporting the } \\
\text { social } \\
\text { environment } \\
\end{array}$ & Yes & Yes & Yes/No & Yes/No \\
\hline $\begin{array}{l}\text { Additional } \\
\text { motivation }\end{array}$ & Yes & Yes & Yes/No & No \\
\hline $\begin{array}{l}\text { Emotional } \\
\text { readiness for } \\
\text { childbirth }\end{array}$ & $\begin{array}{c}\text { Joyful } \\
\text { anticipation }\end{array}$ & $\begin{array}{c}\text { Anxiety } \\
\text { about your } \\
\text { health and } \\
\text { the health } \\
\text { of your } \\
\text { child / Calm } \\
\text { expectation } \\
\text { based on } \\
\text { experience } \\
\text { and } \\
\text { awareness }\end{array}$ & $\begin{array}{l}\text { Fear of childbirth } \\
\text { as something } \\
\text { new and } \\
\text { unknown / } \\
\text { Anxiety } \\
\text { associated with } \\
\text { sociocultural } \\
\text { factors }\end{array}$ & $\begin{array}{l}\text { Fear of childbirth } \\
\text { as something new } \\
\text { and unknown / } \\
\text { Calm expectation } \\
\text { based on } \\
\text { experience and } \\
\text { awareness }\end{array}$ \\
\hline
\end{tabular}

Obviously, with an increase in the level of education, the negative emotional reaction increases, and the number of children (more experience in interacting with the staff of medical institutions) contributes to a decrease in the intensity of the emotional reaction. These results were obtained for a small sample, so they cannot be considered reliable. However, they provide grounds for putting forward appropriate hypotheses and testing them in further research. 


\section{Discussion}

The results of the study indicate that the majority of women have negative experiences of interaction with medical personnel during and immediately after childbirth. This may indicate either that the medical presence is traumatic in itself, or that the Russian healthcare system has an inert, ingrained and traditionally unfriendly model of the attitude of medical personnel towards women in labor.

Based on the interview data, the following factors can be identified that contribute to the strengthening of the negative psychological effects of interaction with medical personnel:

- psychological unreadiness for childbirth, combined with the need to shift responsibility for the process onto someone;

- poor awareness of the unfavorable possibilities of pregnancy and childbirth, which puts a woman in a dependent position on doctors and forces her to accept any options of medical intervention imposed by them;

- the prevailing authority of medical workers; confidence in their competence and infallibility, which has deep sociocultural roots;

- legal illiteracy;

- lack of additional motivating factors: if a woman gives birth to a child "just for herself", because she wants to, and at the same time she does not do it under the pressure of the social environment or stereotypes, does not feel the religious rootedness of the act of birth ("be fruitful and multiply"), experience the injury of interaction with medical personnel is more painful and long-lasting;

- no threat to the life and health of the mother and / or child: if a woman believes that the medical staff "saved" her or her baby, she is more lenient towards the rudeness and corruption of the medical staff;

- unrealistic expectations from the situation of childbirth and interaction with the medical system;

- preliminary agreement with a medical institution or a specific specialist: the presence of such an agreement makes a woman feel confident and protected, but when the agreement is violated for no apparent reason, it becomes a shock, the woman is not ready for such a situation and does not know how to behave.

We see at least three possibilities of influencing the situation from the standpoint of perinatal pedagogy.

The first two possibilities were mentioned at the beginning of the article. They are the subject of discussion in many scientific publications: training of medical personnel to be more attentive and responsive to pregnant and giving birth women, as well as various options for preparing pregnant women for childbirth, including psychological trainings, exercises, information about the physiology of pregnancy and childbirth.

However, we believe that the impact on medical personnel cannot be sufficiently effective in the near future, since the personnel behavior model has deep sociocultural roots and requires the transformation of the entire system not only in the field of obstetrics and gynecology, but also the health care system as a whole. Training for pregnant women is obviously effective, but not enough, since it mainly affects the issues of subjective wellbeing, health status, physiological processes, but not the problems of communication with medical personnel and emotional attitudes towards her.

Therefore, the third possibility of influencing the situation is of fundamental importance: perinatal pedagogy should include components dedicated to communication between the family and medical personnel and the medical system as a whole. It is important that these components include not only theoretical but also practical components.

We offer the following list of necessary knowledge, skills and abilities that should be formed through perinatal pedagogy in expectant mothers: 
- an idea of the physiology of pregnancy and childbirth in an extended version: a woman should imagine what opportunities she has, what is the norm, what are the signs of abnormal pregnancy and childbirth; she must clearly understand what the consequences of any of her choices will be, and not from the words of a doctor pursuing her own interests, but based on knowledge obtained from independent sources;

- legal literacy: a woman should have an idea of her rights, which she has as a patient, and the responsibilities of medical personnel, what is allowed and what is not, what supervisory and higher authorities exist; it will also be useful for a woman to have an idea of the methods of recording events and facts that she can use while in a medical institution;

- women need to be informed about the attitude of medical personnel that they are likely to encounter in a medical facility; romanticizing, hiding real prospects, embellishing facts does not protect the woman in labor, but prepares the way for a deeper and more painful trauma;

- trainings are needed to increase self-confidence and take responsibility for oneself, the child, the process of childbirth and further destiny;

- the ability to say "no" and insist on one's own: such situations need not only to be discussed and pronounced, but to be played repeatedly, to train the necessary reactions.

It is also advisable to influence the attitude of a pregnant woman to the situation that she will have to face. This does not mean that women in labor should be taught that staff rudeness and extortion are the norm to be followed to accept. But a woman needs to feel that she can control and change the situation, that something depends on her behavior. This can be facilitated by role-playing games at the stage of preparation for childbirth, as well as the development of alternative options: a woman should have a backup plan of action in case, for example, she is denied medical care (as a measure of psychological pressure) or the staff does not provide all the necessary information.

\section{Conclusion}

The results of the study confirm the hypothesis that interaction with the personnel of medical institutions is a traumatic experience for Russian women in labor, the reason for which is the unpreparedness of expectant mothers for this contact. An authoritarian style of interaction with a woman in labor, abusive treatment (on the verbal and bodily level), corrupt demands, disregard for the interests of the child and mother, lack of opportunities for informed consent, incompetence, disregard for the patient's health and wishes - this is a list of those facts that make the most important a woman's life experience of childbirth traumatic.

Currently, there are methods and practices aimed at creating a more attentive and responsive attitude of the staff of maternity hospitals to patients, as well as methods aimed at preparing pregnant women for childbirth, including the removal of fear and anxiety, the development of physiological practices that should reduce pain and alleviate the course of the generic process.

However, we believe that this is not enough. With an inert health care system that cannot be changed overnight, there is a clear need to prepare women to face the system. For this, it is advisable to raise awareness of the physiology of pregnancy and childbirth, legal literacy, to train women in the skills of defending their interests, to form an idea of their own responsibility for themselves and their child. There is also a demand for the formation of a more positive attitude towards the process of childbirth, towards the fact of the birth of a child, towards a new social status. However, this is a more complex task that requires additional research, modeling of methods and their approbation. 
Also of research interest are demographic and sociocultural factors of the susceptibility of women in labor to the traumatic experience of interaction with the staff of medical institutions. In particular, it is of interest to study on large samples the influence of such factors as the level of education, the presence of additional sociocultural or ideological motivation, the presence or absence of support from the social environment and social institutions, and emotional readiness for childbirth.

In turn, emotional readiness for childbirth and motherhood is an independent subject of research. So, it is important to understand what affects it and what mechanisms of its formation exist in those cases when this does not occur naturally.

Thus, the subject field of perinatal pedagogy should be expanded by including teaching pregnant women productive communication with the staff of medical institutions and the ability to defend and protect their interests.

\section{References}

1. Y. Suetsugu, M. Haruna, K. Kamibeppu, BMC Pregnancy and Childbirth 20 (1) (2020). DOI: https://doi.org/10.1186/s12884-020-03099-0.

2. Z. Taghizadeh, A. Irajpour, M. Arbabi, Iranian Red Crescent Medical Journal 15 (10) (2013). DOI:10.5812/ircmj.10572.

3. D. Huang, L. Dai, T. Zeng, H. Huang, M. Wu, M. Yuan, K. Zhang, Asian Nursing Research 13, 270-276 (2019). DOI: https://doi.org/10.1016/j.anr.2019.10.002.

4. M. Taheri, A. Takian, Z. Taghizadeh, N. Jafari, N. Sarafraz, Reproductive Health 15 (2018). May. DOI: 10.1186/s12978-018-0511-x.

5. J. Patterson, C.J.H. Martin, T. Karatzias. Disempowered midwives and traumatised women: Exploring the parallel processes of care provider interaction that contribute to women developing Post Traumatic Stress Disorder (PTSD) post childbirth, Midwifery. 76, 21-35 (2019). DOI: https://doi.org/10.1016/j.midw.2019.05.010/.

6. S.C. Shabot, Feminist Theory. APR (2020). DOI: 10.1177/1464700120920764.

7. Z.B. Ardakani, M. Navabakhsh, F. Ranjbar, S. Tremayne, M.M. Akhondi, A.M. Tabrizi, International Journal of Women's Health and Reproduction Sciences 8 (3), 245-258 (2020). DOI: 10.15296/ijwhr.2020.41.

8. M. Hollander, E. de Miranda, A.M. Smit, I. de Graaf, F. Vandenbussche, J. van Dillen, L. Holten, PLOS ONE 15 (2) (2020). DOI: 10.1371/journal.pone.0229069.

9. G. Aynaci, Journal Of Basic And Clinical Health Sciences 4 (2), 160-167 (2020). DOI: 10.30621/jbachs.2020.990.

10. H.W. Kim, D.H. Kim, H.Y. Lee, Y.J. Lee, H.Y. Ahn, International Journal Of Environmental Research And Public Health 17 (7) (2020). DOI: 10.3390/ijerph17072460.

11. D. Saxbe, K.T. Horton, A.B. Tsai, Journal of Family Psychology 32 (2), 262-268 (2018). DOI: https://doi.org/10.1037/fam0000365.

12. S. Honikman, S. Field, S. Cooper, Transcultural Psychiatry 57 (1) (2020). DOI: $10.1177 / 1363461519844640$.

13. C.L. Cummings, Seminars in Perinatology 40 (4), 261-269 (2016). DOI: https://doi.org/10.1053/j.semperi.2015.12.016.

14. S. Wennerström, A.-K. Dykes, Journal of Reproductive and Infant Psychology (2020). DOI: $10.1080 / 02646838.2020 .1761013$. 
15. B.M.J. Munkhondya, T.E. Munkhondya, E. Chirwa, H. Wang, BMC Pregnancy and Childbirth 20 (1), (2020). DOI: https://doi.org/10.1186/s12884-019-2717-5.

16. Z. Hajarian Abhari, F.Z. Karimi, Z. Taghizdeh, S.R. Mazloum, S.M.A. Nekah, Journal of Maternal-Fetal \& Neonatal Medicine FEB (2020). DOI: 10.1080/14767058.2020.1730799. 